\title{
The prevalence of selected risk factors for non-communicable diseases in Hargeisa, Somaliland: a cross-sectional study
}

Soheir H. Ahmed ${ }^{1,2^{*}}$, Haakon E. Meyer ${ }^{2,3}$, Marte K. Kjøllesdal ${ }^{2}$, Niki Marjerrison², Ibrahimu Mdala², Aung Soe Htet ${ }^{4}$, Espen Bjertness ${ }^{2}$ and Ahmed A. Madar ${ }^{2}$

\begin{abstract}
Background: Non-communicable diseases (NCDs), particularly cardiovascular diseases, diabetes, respiratory conditions and cancers, are the most common causes of morbidity and mortality globally. Information on the prevalence estimates of NCD risk factors such as smoking, low fruit \& vegetable intake, physical inactivity, raised blood pressure, overweight, obesity and abnormal blood lipid are scarce in Somaliland. The aim of this study was to determine the prevalence of these selected risk factors for NCDs among 20-69 year old women and men in Hargeisa, Somaliland.
\end{abstract}

Methods: A cross-sectional study was conducted in five districts of Hargeisa (Somaliland), using the STEPwise approach to noncommunicable disease risk factor surveillance (STEPS) to collect data on demographic and behavioral characteristics and physical measurements $(n=1100)$. The STEPS approach is a standardized method for collecting, analysing and disseminating data on NCD risk factor burden. Fasting blood sugar, serum lipids (total cholesterol, low-density lipoprotein (LDL), high-density lipoprotein (HDL), and triglycerides) were collected in half of the participants.

Results: The vast majority of participants had $\leq 1$ serving of fruits daily (97.7\%) and $\leq 1$ serving of vegetables daily (98.2\%). The proportion of participants with low physical activity levels was $78.4 \%$. The overall prevalence of high salt intake was $18.5 \%$. The prevalence of smoking and khat chewing among men was 27 and $37 \%$ respectively, and negligible among women. In women, the prevalence of hypertension increased from 15\% in the age group 20-34 years to 67\% in the age group 50-69 years, the prevalence of overweight and obesity $\left(\mathrm{BMI} \geq 25 \mathrm{~kg} / \mathrm{m}^{2}\right.$ ) from 51 to $73 \%$, and the prevalence of diabetes from 3 to $22 \%$. Similar age-trends were seen in men,

Conclusion: Most of the selected risk factors for noncommunicable diseases were high and increased by age in both women and men. Overweight and obesity and low physical activity needs intervention in women, while hypertension and low fruit and vegetable consumption needs intervention in both men and women. Somaliland health authorities should develop and/or strengthen health services that can help in treating persons with hypertension and hyperlipidaemia, and prevent a future burden of NCDs resulting from a high prevalence of NCD risk factors.

Keywords: STEPs survey, Prevalence, Non-communicable disease risk factors, Somaliland

\footnotetext{
* Correspondence: asliahmed@live.com

${ }^{1}$ College of Medicine \& Health Science, University of Hargeisa, Hargeisa,

Somaliland

${ }^{2}$ Department of Community Medicine and Global Health, Institute of Health

and Society, University of Oslo, Oslo, Norway

Full list of author information is available at the end of the article
}

(c) The Author(s). 2019 Open Access This article is distributed under the terms of the Creative Commons Attribution 4.0 International License (http://creativecommons.org/licenses/by/4.0/), which permits unrestricted use, distribution, and reproduction in any medium, provided you give appropriate credit to the original author(s) and the source, provide a link to the Creative Commons license, and indicate if changes were made. The Creative Commons Public Domain Dedication waiver (http://creativecommons.org/publicdomain/zero/1.0/) applies to the data made available in this article, unless otherwise stated. 


\section{Background}

Epidemiological and demographic transitions are in progress in low- and middle-income countries [1], leading to an increasing burden of non-communicable diseases (NCDs). According to the World Health Organization (WHO), the main types of NCDs are cardiovascular diseases (CVDs), cancer, chronic pulmonary obstructive disease (COPD) and diabetes [2]. These NCDs caused 39.8 million global deaths in 2015 [3]. Nearly three-quarters of all NCDs deaths and the majority of premature deaths occur in lowand middle-income countries and before the age of 70 years [4]. NCDs such as CVDs are a primary health concern and a major cause of morbidity and mortality worldwide [5].

Behavioural and metabolic risk factors both contribute significantly to NCDs. They are often interrelated and include unhealthy diet, insufficient physical activity, smoking, excessive use of alcohol, raised blood pressure, overweight and obesity, and abnormal blood lipid levels $[6,7]$. Raised blood pressure, dyslipidaemia and smoking account for the majority cause of heart attack and strokes $[8,9]$. Further, sociodemographic factors such as age, gender and education have been associated with increased NCDs risk [10].

Somaliland (formerly North Somalia) has a population estimated at 4.5 million people, of which approximately $53 \%$ resides in urban areas [11]. Health indicators for Somaliland are among the worst in Sub-Saharan Africa (SSA), with key issues being related to poor governance and inadequate financial resources [12]. Data about NCDs and their risk factors in this region are scarce. We have previously reported that the prevalence of overweight and obesity was significantly higher among Somalis in Oslo, Norway compared to Hargeisa, Somaliland [13], and according to the Ministry of Health of Somaliland, unhealthy lifestyle, including physical inactivity, smoking and chewing khat, has led to an increase in NCDs [14]. Urbanization has been identified as a root cause of the increasing prevalence of NCDs and their risk factors in sub-Saharan Africa [15]. In Hargeisa, the urban society might have adopted a new sedentary lifestyle and the return of the diaspora might bring negative aspects of Western lifestyles, increasing the population's risk of NCDs [14]. Insight into the prevalence of selected risk factors for NCDs in Somaliland is important, as the country is currently undergoing rapid urbanization and epidemiological transitions [16, 17]. A rise in NCDs and their risk factors will add a high burden to an already pressed health system due to infectious diseases. The aim of the present study is to determine the prevalence of selected risk factors for NCDs among 20-69 year old women and men in Hargeisa, Somaliland.

\section{Methods}

\section{Study design and sampling}

A cross-sectional study was carried out in Hargeisa (capital of Somaliland) according to the WHO STEPwise approach to chronic disease risk factor surveillance [18], between March and September 2016. The STEPS approach is a standardized method for collecting, analysing and disseminating data on NCDs and their risk factors' burden [18]. We included all three STEPS: STEP (1) Questionnaire survey, including the socio-demographic characteristics, behaviours and dietary habits, and history of hypertension and diabetes; STEP (2) Physical measurements, including anthropometric measurements and blood pressure, and STEP (3) A laboratory investigation of fasting blood glucose and fasting lipid profiles. The STEPS survey has not been validated among Somalis, but it has been pilot tested in the study setting.

Before the inception of the study, two study teams were selected and underwent three days of training before the study implementation. A pilot study was conducted in 20 households and it did not lead to any modification of the questionnaire or measurement procedures (weight, height, waist and hip circumference and blood pressure). The selection criteria were women and men aged 20-69 years. Exclusion criteria were confirmed pregnancy or those diagnosed with terminal or incapacitating illnesses.

Due to the lack of data on the prevalence of the selected risk factors on the population under study, the sample size was calculated using the diabetes prevalence of $4 \%$ [19]. There is no population registry in Somaliland, and the only available registry is the number of households. Each household has a unique number. Hargeisa city composes of five major districts, of which each district is further subdivided into four main subdistricts. The sample design for the survey was two-stage cluster sampling and the 20 subdistricts were the primary sampling unit (PSU) (first stage). Out of the twenty PSUs, ten were randomly selected and at the second stage, 1100 households were randomly selected from the ten subdistricts based on the probability proportionate to size (PPS) in each subdistrict.

In each selected household, all eligible individuals aged 20-69 years living in the house were listed in a Kish grid [20]. The Kish method addresses the selection of gender and different age groups in the sample. Men and women were listed in order of decreasing age and given a rank number. If the selected person rejected participation, the next person on the Kish grid was selected until there was one person from each household participating in the study. If there was nobody at home on the day of the study, a notification letter was left at the door, and we returned the next day until we had a participant from each house. None of the randomly selected households 
were empty or refused to participate in the study and we included one person from each of the randomly selected 1100 households. A total of 195 eligible men were selected. However, 50 men either refused or could not meet after several contacts, resulting in $74.3 \%(145 / 195)$ of the invited men to be included in the study. Among women only three refused to participate, which means 99.7\% (955/958) of those invited then participated.

\section{Data collection and measurements}

Participants were involved in the study for two days: day one for STEP 1 and 2 (questionnaire, anthropometric and blood pressure measurements), and day two for STEP 3 (laboratory tests).

Step 1 involved the survey questionnaire consisting of core information (age, sex, marital status and education) and behavioural variables (fruit and vegetable intake, physical activity, smoking and khat). Medical history included questions on medication for raised blood pressure, diabetes and raised cholesterol.

Step 2 involved physical measurements including weight, height, waist circumference and blood pressure. Weight and height were measured with participants standing without shoes and wearing light clothing. Body weight (kilograms) was recorded to the nearest $0.1 \mathrm{~kg}$ and measured with an Omron medical scale that was checked every day with a known weight. Height (centimetres) was recorded to the nearest $0.5 \mathrm{~cm}$ and measured with a manual height-measuring instrument (SECA stadiometer) with participants standing upright with the head in Frankfort plane. Body mass index (BMI) was calculated as weight in kilograms divided by the square of the height in meters $\left(\mathrm{kg} / \mathrm{m}^{2}\right)$. Waist circumference (WC) was measured at the midpoint between the lower margin of the last palpable rib and the top of the iliac crest, using a measuring tape to the nearest $0.1 \mathrm{~cm}$ with the subject standing and breathing normally. Blood pressure was measured 3 times at one minute intervals using an automatic, validated device (Omron HBP 1300) [21], with participants seated and after resting for approximately $5 \mathrm{~min}$.

Step 3 involved a laboratory test. Fasting venous blood samples were collected from participants to determine the concentration of serum glucose and lipids (fasting serum glucose (FSG), total cholesterol (TC), high-density lipoprotein (HDL) cholesterol, low-density lipoprotein (LDL) cholesterol, and triglycerides (TG)). In Hargeisa Group Hospital, blood samples were collected in serum-separator gel tubes and centrifuged after $30 \mathrm{~min}$. Serum and plasma were then separated and frozen in aliquots at $-30{ }^{\circ} \mathrm{C}$ the same day until being shipped to Oslo, Norway where they were analysed as one batch at the Fürst Medical Laboratory (http://www.furst.no/), which has been accredited by the Norwegian Accreditation according to the standard
NS-EN ISO 15189 TEST 209. The inter-assay coefficients of variation were $1.3 \%$ (TC), 1.6\% (LDL-cholesterol), $1.8 \%$ (HDL-cholesterol), and 3.8\% (TG). Total cholesterol, LDL-cholesterol, HDL-cholesterol, and TG were measured using an enzymatic method (ADVIA 2400 Siemens)

\section{Variables}

We classified age (years) into three groups for women (20-34, 35-49 and 50-69) and for men into two groups due to a smaller number of participants (20-34 and 3569). Overweight and obesity was defined as BMI $\geq 25 \mathrm{~kg} /$ $\mathrm{m}^{2}$ [22]. High waist circumference was classified according to the European cut-off $(>94 \mathrm{~cm}$ for men, $>80 \mathrm{~cm}$ for women) because cut-offs for SSA were not available [23]. Hypertension was defined as systolic blood pressure $(\mathrm{SBP}) \geq 140 \mathrm{mmHg}$, diastolic blood pressure (DBP) $\geq 90 \mathrm{mmHg}$, and/or being on blood pressure-lowering medication [4].

Diabetes was defined as FSG $\geq 7.0 \mathrm{mmol} / \mathrm{l}$ and/or being on medication [23], and high cholesterol level as TC/HDL ratio $\geq 5.0$ and/or being on medication, and high triglycerides as TG $\geq 1.7 \mathrm{mmol} / 1[18,24]$.

High salt intake was defined as answering often or always to at least one of the questions regarding salt intake (adding salt to the plate after food has been served, adding salty seasoning or a salty sauce, and eating processed food high in salt). Respondents were asked for the number of days they ate fruit and vegetables in a typical week. Servings were measured by showing pictorial show-cards. A low fruit and vegetables consumption was defined as $<3$ portions of fruit and vegetables per day, due to a low number of participants consuming $>5$ servings.

Physical activity was measured by asking the respondents about their weekly and daily vigorous and moderate activities during work, leisure time and during transport, and the time spent in these activities. Low physical activity was defined as achieving less than 600 MET-minutes per week in accordance with WHO guidelines, determined by the intensity of exercise undertaken (MET level) multiplied by the minutes participated per week (minutes) [25].

\section{Statistical methods}

Descriptive statistics in the form of frequencies (proportions) and means with standard deviations (SD) were used to summarize the data. Associations between categorical variables were established from the Chi-square test and/ or the Fishers' exact test. The Chi-square test was used to assess the association between each categorical variable with gender. In particular, we used a Chisquare test to investigate whether there was a significant increase (trend) of each risk factor across the different 
age groups (a variable with a natural ordering). Age-specific means stratified by gender and age-groups were estimated by using one-way analysis of variance (ANOVA) to test for the differences between the means. All statistical analyses were performed using SPSS version 25.0 (Chicago, Illinois: SPSS Inc.), and differences with a $p$-value $<0.05$ were considered statistically significant.

\section{Results}

\section{Demographic and lifestyle characteristics}

A total of 1100 participants were included in the analysis, with a higher proportion of women $(n=995)$ than men $(n=145)$. All participants underwent anthropometric measurements, while blood samples were drawn from 597 participants $(56.2 \%$ of women and $41.3 \%$ of men). The majority of participants were in the age group 20-34 years (43.3\%) (Table 1). Among women, 66.4\% had no formal education; the corresponding proportion among men was $31.7 \%$. More than two-thirds of the participants were married. Almost all participants had a low fruit and vegetables consumption, physical activity (overall MET < $600 \mathrm{~min} /$ week) was reported among $81.5 \%$ of women and $58.0 \%$ of men. The overall proportion with a high salt intake was $18.5 \%$. Khat chewing (36.6\%) and smoking (26.9\%) was common among men, whereas only $0.3 \%$ of women chewed khat and none smoked (Table 1).

\section{Risk factor profile across age groups}

We observed differences in risk factors levels across age groups. Among women, mean levels of BMI, WC, SBP, DBP, FSG, TG, LDL and TC to HDL ratio increased with age (Table 2). Over all, women had a high proportion of overweight and obesity (62.9\%) compared to men (23.4\%), while women (36.1\%) and men (33.1\%) and had a similar proportion of hypertension. Both high cholesterol and high triglycerides were higher in men $(36.7 \%$ and 35.0) than in women (22.3 and 19.7\%, respectively) (Fig. 1).

Further, the prevalence of hypertension, overweight and obesity, high WC, diabetes, high TG and high cholesterol increased with age (Table 3). Only a high salt intake was higher in younger compared to older women $(26.9 \%$ vs $13.3 \%)$.

Among men, the mean levels of BMI, WC, SBP, DBP, and LDL was higher in the oldest age group than among the younger (Table 2), and the prevalence of smoking, khat chewing, hypertension, overweight/obesity and high WC increased with age (Table 3). A low fruit and vegetables consumption was found in both age groups, but was most pronounced among the youngest men. The prevalence of diabetes ranged from 3.4\% in the youngest age group to $22.2 \%$ in the oldest among women, and from 7.4 to $25.0 \%$ among men. Corresponding proportions for hypertension were 14.8 and $67.2 \%$ among women and 17.1 to $50.7 \%$ among men. Around twothirds of women, but less than one-third of men were overweight/obesity and/or had high WC, with the highest proportions for each measure found in the oldest age group.

\section{The proportion of behavioural risk factors by level of education}

We examined educational differences in behaviour risk factors but we found no differences, only that khat chewing was higher among the less educated men compared to those had university education (Table 4).

\section{Discussion}

This study reported that selected risk factors of noncommunicable diseases were prevalent among both women and men in Hargeisa, suggesting a significant threat to the Somali population related to an upcoming NCDs epidemic. For most risk factors, the prevalence increased with age. Smoking and khat chewing were a problem among men only, whereas a higher proportion of women than men reported low levels of physical activity. Overweight and obesity was higher in women and high blood pressure was high in both women and men. Age is an unmodifiable risk factor for chronic diseases across all populations. In our study, age was associated with the increasing prevalence of many of the investigated selected NCD risk factors in both women and men, and our findings are consistent with studies that were conducted among other Sub-Saharan African countries [26, 27].

In general, low fruit and vegetable consumption was highly prevalent among women and men, and it was higher than what has been previously reported in South Africa [28]. High consumption of fruit and vegetables is documented to reduce the risk of coronary heart disease, stroke, obesity and possibly some types of cancer [29]. Accessibility and affordability play important roles in the consumption of fruit and vegetables in some low- and middle-income countries [30]. In Somaliland, a big portion of fruits and vegetables are imported from abroad, and thus their consumption depends on several factors including price and seasonal availability. However, in the Somali methods of food preparation, most vegetables are cooked with sauces and stewing, and thus those cooked vegetables are not considered a vegetable consumption nor are fruits consumed as drinks. Thus, vegetable and fruit intake levels in this study may be underreported.

The high proportion of overweight and obesity among women compared to men has been reported previously [13], and is consistent with other findings [31]. The high 
Table 1 Characteristics of study participants by gender

\begin{tabular}{|c|c|c|c|c|}
\hline & $\begin{array}{l}\text { Women }(n=955) \\
\text { N (\%) }\end{array}$ & $\begin{array}{l}\text { Men }(n=145) \\
\text { N (\%) }\end{array}$ & $\begin{array}{l}\text { Total }(n=1100) \\
\text { N (\%) }\end{array}$ & $P$-value* \\
\hline \multicolumn{5}{|l|}{ Age (years) } \\
\hline $20-34$ & $402(42.5)$ & $76(52.4)$ & $478(43.5)$ & \multirow[t]{3}{*}{0.015} \\
\hline $35-49$ & $290(30.4)$ & $28(19.3)$ & $318(28.9)$ & \\
\hline $50-69$ & $263(27.5)$ & $41(28.3)$ & $304(27.6)$ & \\
\hline \multicolumn{5}{|l|}{ Marital status } \\
\hline Never married & $165(17.2)$ & $60(41.4)$ & $224(20.4)$ & \multirow[t]{4}{*}{$<0.001$} \\
\hline Currently married & $749(78.4)$ & $82(56.6)$ & $831(75.5)$ & \\
\hline Divorced & $359(3.7)$ & $2(1.4)$ & $37(3.4)$ & \\
\hline Widowed & $6(0.6)$ & $1(0.7)$ & $0.6(7)$ & \\
\hline \multicolumn{5}{|l|}{ Education } \\
\hline No education & $634(66.4)$ & $46(31.7)$ & $680(61.8)$ & \multirow[t]{4}{*}{$<0.001$} \\
\hline Primary education & $185(19.4)$ & $23(15.9)$ & $208(18.9)$ & \\
\hline Secondary education & $74(7.7)$ & $31(21.4)$ & $105(9.5)$ & \\
\hline University education & $62(6.5)$ & $45(31.0)$ & $107(9.7)$ & \\
\hline \multicolumn{5}{|l|}{ Fruit consumption } \\
\hline No servings/day & $240(25.1)$ & $24(16.6)$ & $264(24.0)$ & \multirow[t]{4}{*}{0.083} \\
\hline 1 servings/day & $695(72.8)$ & $116(80.0)$ & $811(73.7)$ & \\
\hline 2 servings/day & $8(0.8)$ & $3(2.1)$ & $11(1.0)$ & \\
\hline 3 servings/day & $12(1.3)$ & $2(1.4)$ & $14(1.3)$ & \\
\hline \multicolumn{5}{|l|}{ Vegetable consumption } \\
\hline No servings/day & $270(28.3)$ & $36(24.8)$ & $306(27.8)$ & \multirow[t]{4}{*}{0.095} \\
\hline 1 servings/day & $669(70.1)$ & $105(72.4)$ & $774(70.4)$ & \\
\hline 2 servings/day & $4(0.4)$ & $3(2.1)$ & $7(0.6)$ & \\
\hline 3 servings/day & $12(1.3)$ & $1(0.7)$ & $13(1.2)$ & \\
\hline \multicolumn{5}{|c|}{ Fruit and vegetables consumption } \\
\hline$<3$ servings/day & $930(97.4)$ & $138(95.2)$ & $1068(97.1)$ & \multirow[t]{2}{*}{0.140} \\
\hline$>3$ servings/day & $25(2.6)$ & $7(4.8)$ & $32(2.9)$ & \\
\hline \multicolumn{5}{|l|}{ Physical activity, MET-min } \\
\hline$>600$ & $176(18.5)$ & $60(42.0)$ & $236(21.6)$ & \multirow[t]{2}{*}{$<0.001$} \\
\hline$<600$ & $775(81.5)$ & $83(58.0)$ & $858(78.4)$ & \\
\hline \multicolumn{5}{|l|}{ Salt ${ }^{a}$} \\
\hline Often/always & $171(17.9)$ & $32(22.1)$ & $203(18.5)$ & \multirow[t]{2}{*}{0.233} \\
\hline Others (never \& rarely) & $782(82.1)$ & $113(77.9)$ & $895(81.5)$ & \\
\hline \multicolumn{5}{|l|}{ Current smoker } \\
\hline Yes & - & $39(26.9)$ & $39(3.5)$ & \multirow[t]{2}{*}{$<0.001$} \\
\hline No & $955(100)$ & $93(73.1)$ & $1045(96.5)$ & \\
\hline \multicolumn{5}{|l|}{ Current khat chewers } \\
\hline Yes & $3(0.3)$ & $53(36.6)$ & $56(5.1)$ & \multirow[t]{2}{*}{$<0.001$} \\
\hline No & $948(99.7)$ & $92(63.4)$ & $1040(94.9)$ & \\
\hline
\end{tabular}

* $P$-value of the $X^{2}$ test for differences between women and men. ${ }^{a}$ Combined all types of salt intake (added salt, salt sauces and processed food high in salt)

prevalence of overweight and physical inactivity in women are likely interrelated [32, 33], as physical inactivity is a risk factor for obesity and other chronic diseases [34]. Cultural norms such as a desire to be overweight to demonstrate wealth, and a lack of social and environmental support, may be leading to reduced participation in physical activity [35]. In some populations, lower physical activity among women has been 
Table 2 Age- and gender-specific distribution of mean (SD) anthropometric and biochemical risk factors

\begin{tabular}{|c|c|c|c|c|c|c|c|}
\hline \multirow[b]{2}{*}{ Age (years) } & \multicolumn{4}{|c|}{ Women $(n=955)^{\mathrm{a}}$} & \multicolumn{3}{|c|}{ Men $(n=145)^{\mathrm{a}}$} \\
\hline & $\begin{array}{l}20-34 \text { years, } \\
\text { Mean } \pm \text { SD }\end{array}$ & $\begin{array}{l}35-49 \text { years, } \\
\text { Mean } \pm S D\end{array}$ & $\begin{array}{l}50-69 \text { years, } \\
\text { Mean } \pm S D\end{array}$ & $p$-value & $\begin{array}{l}20-34 \text { years, } \\
\text { Mean } \pm \text { SD }\end{array}$ & $\begin{array}{l}35-69 \text { years, } \\
\text { Mean } \pm \text { SD }\end{array}$ & $p$-value \\
\hline $\mathrm{BMI}\left(\mathrm{kg} / \mathrm{m}^{2}\right)$ & $25.5 \pm 5.6$ & $28.6 \pm 5.9$ & $28.3 \pm 5.6$ & $<0.001$ & $20.8 \pm 4.5$ & $23.5 \pm 4.2$ & $<0.001$ \\
\hline$W C(\mathrm{~cm})$ & $81.4 \pm 13.6$ & $91.2 \pm 13.4$ & $91.2 \pm 13.4$ & $<0.001$ & $75.0 \pm 11.4$ & $89.5 \pm 11.5$ & $<0.001$ \\
\hline $\mathrm{SPB}(\mathrm{mmHg})$ & $115.8 \pm 13.5$ & $128.7 \pm 21.4$ & $146.5 \pm 29.1$ & $<0.001$ & $123.4 \pm 22.0$ & $136.7 \pm 31.8$ & 0.004 \\
\hline $\mathrm{DBP}(\mathrm{mmHg})$ & $78.9 \pm 9.1$ & $85.8 \pm 12.4$ & $89.2 \pm 14.2$ & $<0.001$ & $79.0 \pm 10.1$ & $86.8 \pm 14.0$ & $<0.001$ \\
\hline FSG (mmol/L) & $4.8 \pm 1.4$ & $5.6 \pm 2.6$ & $5.9 \pm 2.9$ & $<0.001$ & $4.9 \pm 1.7$ & $5.8 \pm 2.1$ & 0.073 \\
\hline $\mathrm{TC}(\mathrm{mmol} / \mathrm{L})$ & $4.4 \pm 1.0$ & $4.6 \pm 0.9$ & $5.1 \pm 0.8$ & $<0.001$ & $4.2 \pm 1.3$ & $4.8 \pm 0.9$ & 0.053 \\
\hline $\mathrm{HDL}(\mathrm{mmol} / \mathrm{L})$ & $1.1 \pm 0.3$ & $1.1 \pm 0.3$ & $1.1 \pm 0.3$ & 0.457 & $0.9 \pm 0.3$ & $1.0 \pm 0.2$ & 0.127 \\
\hline TC to HDL ratio & $3.9 \pm 1.0$ & $4.2 \pm 1.1$ & $4.5 \pm 0.9$ & $<0.001$ & $4.3 \pm 0.9$ & $4.7 \pm 0.9$ & 0.118 \\
\hline Triglyceride $(\mathrm{mmol} / \mathrm{L})$ & $1.0 \pm 0.5$ & $1.4 \pm 0.6$ & $1.6 \pm 0.9$ & $<0.001$ & $1.5 \pm 1.9$ & $1.6 \pm 0.7$ & 0.739 \\
\hline LDL (mmol/L) & $2.5 \pm 0.9$ & $2.8 \pm 0.9$ & $3.1 \pm 1.0$ & $<0.001$ & $2.3 \pm 1.1$ & $3.0 \pm 0.8$ & 0.004 \\
\hline
\end{tabular}

${ }^{a} \mathrm{n}$ is lower among those who did blood sample (women $n=537$, men $=60$ )

Abbreviations: BMI Body mass index, WC Waist circumference, SBP Systolic blood pressure, DBP Diastolic blood pressure, FSG Fasting serum glucose, TC Total cholesterol, HDL High-density lipoprotein, LDL Low density lipoprotein. TC to HDL ratio: total cholesterol to High-density lipoprotein

attributed to gender norms, including gender constraints and a lack of suitable dresses for exercise [36]. Undertaking physical activity in a fitness centre in Hargeisa for women requires gender-separated facilities, which are limited.

Additionally, nearly no women smoked or chewed khat as previously reported [37]. There may be sociocultural explanations for this, as smoking could be seen as a normal part of being a man [38]. Additionally, chewing khat among women in some societies is considered socially unacceptable and thus is rarely used [39]. Meanwhile, one in three men chewed khat and one in four smoked. The crude prevalence of current smoking among men in Hargeisa, at 26.9\%, was higher than in Ethiopia, Benin and Ghana, but lower than in Sierra Leone, Lesotho and Madagascar [40]. Such a prevalence is concerning, as smoking alone is a well-established and major risk factor for CVD, cancer and COPD, and is the second leading cause for CVD mortality after high blood pressure [41].

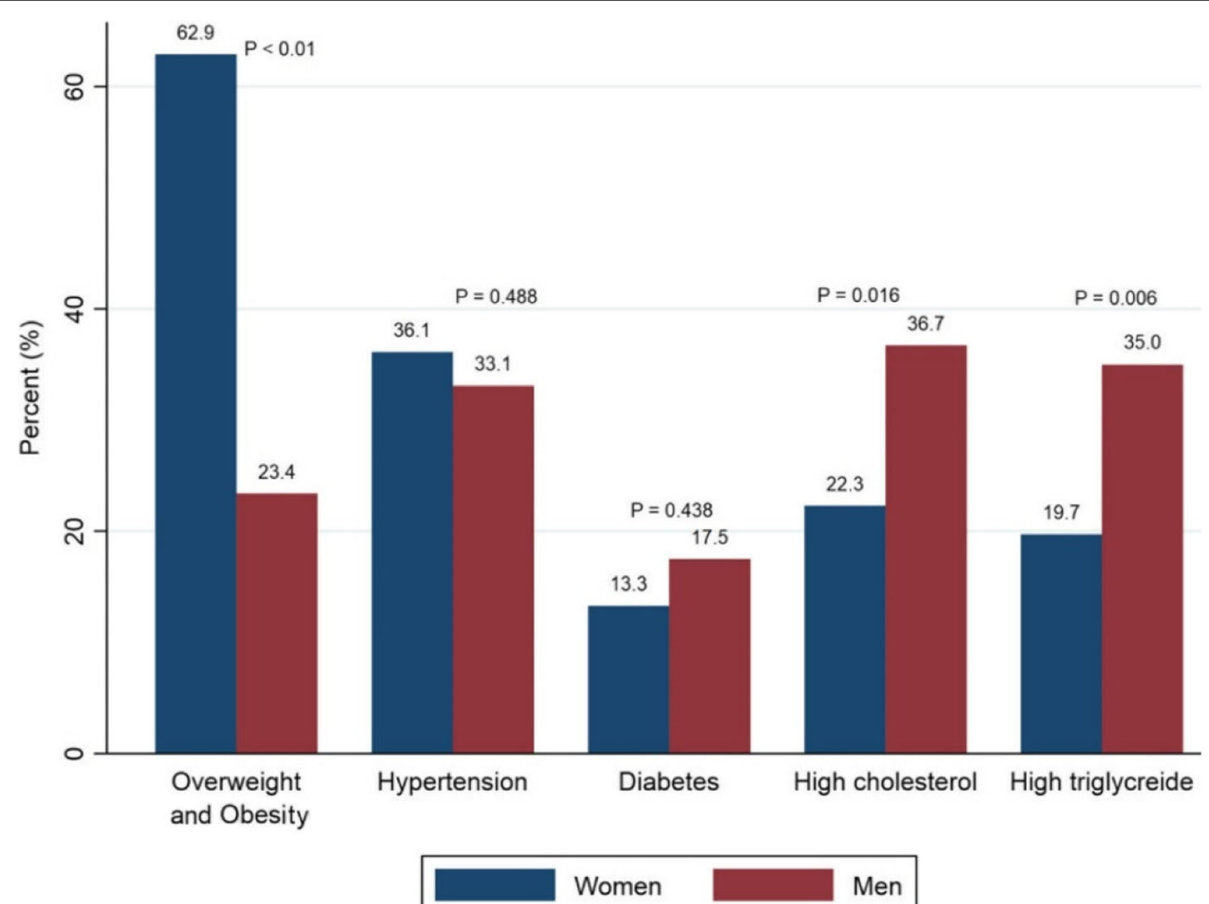

Fig. 1 Proportion of NCDs risk factors by gender ( $P$ value for the gender differences) 
Table 3 Age- and gender-specific prevalence of behavioural, physical and biochemical risk factors

\begin{tabular}{|c|c|c|c|c|}
\hline \multicolumn{5}{|c|}{ Women $(n=955)^{\mathbf{f}}$} \\
\hline Risk factor & $20-34$ years, \% (95\%Cl) & $35-49$ years, $\%(95 \% \mathrm{Cl})$ & 50-69 years, \% (95\%Cl) & Pvalue \\
\hline Low fruit and vegetables consumption & $97.5(95.9,99.0)$ & $96.2(94.0,98.4)$ & $98.5(98.5,96.9)$ & 0.242 \\
\hline High salt intake & $26.9(23.0,31.0)$ & $9.7(6.0,13.0)$ & $13.3(9.0,17.0)$ & $<0.001$ \\
\hline Low physical activity & $81.0(77.1,84.8)$ & $78.5(73.8,83.8)$ & $85.6(81.3,89.8)$ & 0.103 \\
\hline Hypertension & $14.8(11.0,17.9)$ & $37.8(32.2,43.4)$ & $67.2(61.4,72.9)$ & $<0.001$ \\
\hline Overweight and obesity & $50.7(46.0,56.0)$ & $71.0(66.0,76.0)$ & $72.6(67.0,78.0)$ & $<0.001$ \\
\hline High waist circumference & $51.6(47.0,57.0)$ & $81.4(77.0,86.0)$ & $82.1(77.0,87.0)$ & $<0.001$ \\
\hline Diabetes & $3.4(0.9,5.8)$ & $16.3(10.8,21.7)$ & $22.2(15.9,28.5)$ & $<0.001$ \\
\hline High triglycerides & $10.7(6.4,15.0)$ & $21.8(15.5,28.0)$ & $29.0(21.9,36.0)$ & $<0.001$ \\
\hline High cholesterol & $13.6(8.8,18.3)$ & $24.1(17.6,30.6)$ & $31.6(24.3,38.9)$ & $<0.001$ \\
\hline \multicolumn{5}{|c|}{ Men $(n=145)^{\mathbf{E}}$} \\
\hline Risk factor & 20-34 years,\% (95\%Cl) & $35-69$ years,\% (95\%Cl) & NA & ${ }^{*}$ Pvalue \\
\hline Low fruit and vegetables consumption & $98.7(98.7,99.1)$ & $91.3(84.4,98.1)$ & & 0.038 \\
\hline High salt intake & $23.7(14.0,33.0)$ & $20.0(11.0,30.0)$ & & 0.623 \\
\hline Low physical activity & $56.6(45.2,67.9)$ & $59.7(47.6,71.8)$ & & 0.708 \\
\hline Current smoking & $18.4(10.0,27.0)$ & $36.2(25.0,48.0)$ & & 0.016 \\
\hline Current khat chewers & $28.9(19.0,39.0)$ & $44.9(33.0,57.0)$ & & 0.046 \\
\hline Hypertension & $17.1(8.4,25.8)$ & $50.7(38.6,62.8)$ & & $<0.001$ \\
\hline Overweight and obesity & $14.5(16.0,23.0)$ & $33.3(22.0,45.0)$ & & 0.007 \\
\hline High waist circumference & $6.6(1.0,12.0)$ & $40.6(29.0,52.0)$ & & $<0.001^{* *}$ \\
\hline Diabetes & $7.4(-3.1,17.9)$ & $25.0(10.1,39.8)$ & & $0.097^{* *}$ \\
\hline High triglycerides & $25.9(8.2,43.6)$ & $42.4(24.6,60.2)$ & & 0.189 \\
\hline High cholesterol & $20.0(3.1,36.8)$ & $48.6(21.8,56.9)$ & & $0.031^{* *}$ \\
\hline
\end{tabular}

*chi-square test for trend in proportions, ${ }^{* *}$ Fisher's exact test

${ }^{\mathrm{E}} \mathrm{N}$ is lower among those who did blood sample (women $n=537$, men $=60$ )

Low fruit and vegetables consumption ( $<3$ servings of fruits and/or vegetables on average per day), high salt intake (answering often and/or always to at least one of the questions regarding salt intake (adding salt to the plate after food has been served, adding salty seasoning or a salty sauce, and eating processed food high in salt)). Low physical activity (<600 MET-min), current smoking (Yes/No), current khat chewers (Yes/No). Hypertension (SBP $\geq 140 \mathrm{mmHg}$, DBP $\geq 90 \mathrm{mmHg}$ and/or being on blood pressure lowering medication), overweight and obesity (BMI $\geq 25 \mathrm{~kg} / \mathrm{m}^{2}$ ). High waist circumference ( $\geq 80 \mathrm{~cm}$ for women $\& \geq 94 \mathrm{~cm}$ for men), Diabetes ( $\geq 7.0 \mathrm{mmol} / \mathrm{l}$ and/or being on medication). High triglycerides level ( $\geq 1.7 \mathrm{mmol} / \mathrm{l})$. High cholesterol (TC: HDL ratio $\geq 5$ and/or being on medication)

Khat are the fresh leaves that are widely chewed in Yemen and other East African countries, which are chewed for leisure and social purposes [42]. Khat chewing is correlated with various health consequences associated with chronic diseases, such as raised blood pressure and coronary heart disease [43-45]. The high prevalence of khat chewing among men in this study is similar to findings from Ethiopia [46].

Another finding in our study was the higher prevalence of behaviour risk factors like khat and smoking among the older age group of men (35 to 69 years) than the younger (20 to 34 years). Our finding of smoking being higher among the oldest age group is contrary to a previous study conducted among Nigerians [47]. As it is known that smoking and khat chewing are both social habits among men in East African countries, we are unsure if the lower prevalence seen among the younger age group will increase, as they grow older. Little is known about khat chewing in East African countries, and changing trends with the ageing population and rising economy should be further investigated.

We have examined the differences between women and men in overweight and obesity, hypertension and high cholesterol. We found that women had higher overweight and obesity, whereas men had higher high cholesterol than women. However, hypertension was high among both women and men and these metabolic risk factors tend to increase with age. Concerningly, high blood pressure combined with high cholesterol substantially increases CVD risk [48]. The current population can be expected to live longer than previous generations, which will give rise to greater NCD risks among the population and put a greater demand on the health resources of the nation. Coupled with scarce health-care 
Table 4 Gender distribution of behavioural risk factors by level of education

\begin{tabular}{|c|c|c|c|c|}
\hline \multicolumn{5}{|l|}{ Education } \\
\hline & Preschool/Primary & Secondary & University & \\
\hline Women & $(n=819), N(\%)$ & $(n=74), \mathrm{N}(\%)$ & $(n=62), \mathrm{N}(\%)$ & Pvalue $^{*}$ \\
\hline Low fruit and vegetables consumption & $795(97.1)$ & $74(100)$ & $61(98.4)$ & 0.280 \\
\hline High salt intake & $143(17.5)$ & $15(20.3)$ & $13(21.0)$ & 0.682 \\
\hline Low physical activity & $665(81.4)$ & $61(83.6)$ & $49(79.0)$ & 0.796 \\
\hline Men & $(n=69), \mathrm{N}(\%)$ & $(n=31), \mathrm{N}(\%)$ & $(n=45), \mathrm{N}(\%)$ & \\
\hline low fruit and vegetables consumption & $65(94.2)$ & $30(96.8)$ & $43(95.6)$ & 0.188 \\
\hline High salt intake & $14(20.3)$ & $8(25.8)$ & $10(22.2)$ & 0.827 \\
\hline Low physical activity & $42(62.7)$ & $19(61.3)$ & $22(48.9)$ & 0.320 \\
\hline Current smoking & $22(31.9)$ & $8(25.8)$ & $9(20.0)$ & 0.372 \\
\hline Current khat chewers & $33(47.8)$ & $11(35.5)$ & $9(20.0)$ & 0.010 \\
\hline
\end{tabular}

*Pvalue for the chi-square test

Low fruit and vegetables consumption ( $<3$ servings of fruits and/or vegetables on average per day), High salt intake (answering often and/or always to at least one of the questions regarding salt intake (adding salt to the plate after food has been served, adding salty seasoning or a salty sauce, and eating processed food high in salt)). Low physical activity (<600 MET-min), current smoking (Yes/No), current khat chewers (Yes/No)

facilities and financial resources for healthcare, a lack of awareness, prevention and treatment of chronic disease risk factors may further increase CVD morbidity and mortality in Somaliland [49].

\section{Strengths and limitations}

In general, data on the prevalence of risk factors for NCDs among Somalis in the Horn of Africa is very limited, and to our knowledge, this is the first study that has been carried out in Somaliland using the WHO STEPwise approach to noncommunicable disease risk factor surveillance (STEPS). This provides important baseline data on the prevalence of risk factors for CVDs for comparison to other Somali regions and for inclusion in follow-up studies of longitudinal design. The tools used in the study were standardized and checked every morning.

This study was carried out in an urban setting. The sample was drawn from a big city with Somali inhabitants originating from all regions throughout the Horn of Africa. Thus, our results could possibly be representative of other cities in Somaliland and Somalia.

This study has some limitations. The low participation of men in this study limits the interpretation of data pertaining to them. In our survey we used the Kish grid, as the Kish grid addresses the selection of gender and age in a sample, but there is a discussion of whether the Kish grid can provide a representative sample for gender [50]. During the survey, more women were in the households than men. Moreover, fifty eligible men refused or were not available after several contacts. If the selected person was not at home, we left a note that our team would come back next day, and if they were not present for two attempts, we selected the next eligible person from the Kish grid. According to
Somali culture, women are often in the houses during the daytime while men are away working or socializing with other men. Therefore, there also might have been a selection bias among men who were home and included in the study, as they may have been home and willing to participate for special reasons such as poor health or lack of work. Again, results pertaining to the low number of men in this study should be treated cautiously.

The lower number of participants who participated in the blood sample analysis (54.3\%) is also a possible limitation of this study. This might have been due to negative perceptions towards blood sampling in Somali culture or the location of the blood collection was far for some of the participants (health centre). It is possible that those who took the blood tests are those who have a more active awareness of their personal health. However, the BMI, SBP and DBP of the participants who did not take blood samples were not significantly different from the participants in the analysis.

Lastly, recall bias may have been introduced from the questions on the self-reported variables such as that pertaining to vegetable and fruit intake, as it possible that participants didn't report boiled or cooked vegetables (such as cabbage, tomatoes, carrots, and onions) with main dishes such as rice and spaghetti.

\section{Conclusion}

The prevalence of selected NCDs risk factors are high in Somaliland. Overweight and obesity and low physical activity needs intervention in women, while hypertension and low fruit and vegetable consumption needs intervention in both men and women. Policy makers and stakeholders in the health sector need to institute 
nationwide population-based strategies to create awareness about these selected NCDs risk factors, as well as its consequences. In addition, more research should be undertaken to generate representative data on NCDs risk factors differences among urban and rural areas, genders, and socio-economic conditions.

\section{Abbreviations}

ANOVA: Analysis of variance; BMl: Body mass index; Cl: Confidence interval; CVDs: Cardiovascular diseases; MET: Metabolic equivalents; NCDs: Noncommunicable diseases; PSUs: Primary sample units; SSA: SubSaharan Africa; WC: Waist circumference; WHO: World Health Organization

\section{Acknowledgements}

The authors are grateful to the participants, data collectors and Hargeisa Group Hospital. We also thank Dr. Deria Ismail Ereg and University of Hargeisa for facilitating the study.

\section{Authors' contributions}

AAM, HEM and MKK planned the study. SHA carried out the data collection. SHA and IM analysed the data. SHA drafted the manuscript. AAM, HEM, MKK, $E B, N M$ and $A S H$ contributed to the interpretation of the findings and critically revised the manuscript. All authors approved the final version of the manuscript.

\section{Funding}

The study was supported by University of Oslo (UiO).

\section{Availability of data and materials}

The data was stored and/or analysed at the University of Oslo's platform for the processing of sensitive research data, TSD (https://www.uio.no/english/ services/it/research/sensitive-data/). Data is available on reasonable request.

\section{Ethics approval and consent to participate}

The study was approved by the Regional Committee for Medical (study code: 2015/2448 REK South-East) and the Ministry of Health in Somaliland. Written informed consent was obtained from all participants.

\section{Consent for publication}

Not applicable.

\section{Competing interests}

The authors declare that they have no competing interests.

\section{Author details}

${ }^{1}$ College of Medicine \& Health Science, University of Hargeisa, Hargeisa, Somaliland. ${ }^{2}$ Department of Community Medicine and Global Health, Institute of Health and Society, University of Oslo, Oslo, Norway. ${ }^{3}$ Division of Mental and Physical Health, Norwegian Institute of Public Health, Oslo, Norway. ${ }^{4}$ International Relations Division, Ministry of Health and Sports, Nay Pyi, Taw 15011, Myanmar.

Received: 20 December 2018 Accepted: 3 June 2019

Published online: 04 July 2019

\section{References}

1. Kuate Defo B. Demographic, epidemiological, and health transitions: are they relevant to population health patterns in Africa? Glob Health Action. 2014;7. https://doi.org/10.3402/gha.v7.22443

2. World Health Organization (WHO). Noncommunicable diseases 2017 http:// www.who.int/news-room/fact-sheets/detail/noncommunicable-diseases. Accesed 15 July 2018.

3. Wang H, Naghavi M, Allen C, Barber RM, Bhutta ZA, Carter A, et al. Global, regional, and national life expectancy, all-cause mortality, and cause-specific mortality for 249 causes of death, 1980-2015: a systematic analysis for the Global Burden of Disease Study 2015. Lancet. 2016;388(10053):1459-544.

4. World Health Organization (WHO): Global status report on noncommunicable diseases 2014
5. Yach D, Hawkes C, Gould C, Hofman KJ. The global burden of chronic diseases: overcoming impediments to prevention and control. JAMA. 2004; 291(21):2616-22.

6. Buttar HS, Li T, Ravi N. Prevention of cardiovascular diseases: role of exercise, dietary interventions, obesity and smoking cessation. Exp Clin Cardiol. 2005; 10(4):229-49.

7. Sofi F, Innocenti G, Dini C, Masi L, Battistini NC, Brandi ML, et al. Low adherence of a clinically healthy Italian population to nutritional recommendations for primary prevention of chronic diseases. Nutr Metab Cardiovasc Dis. 2006;16(6):436-44.

8. Steyn K, Damasceno A., et al. Lifestyle and related risk factors for chronic diseases. 2006.

9. Boutayeb A, et al. The double burden of communicable and noncommunicable diseases in developing countries. Trans R Soc Trop Med Hyg 2006:100(3):191-9.

10. Phaswana-Mafuya N, Peltzer K, Chirinda W, Musekiwa A, Kose Z, Hoosain E, et al. Self-reported prevalence of chronic non-communicable diseases and associated factors among older adults in South Africa. Glob Health Action. 2013:6. https://doi.org/10.3402/gha.v6i0.20936.

11. Ministry of National Planning and Development: Somaliland In Figure 2015. https://slministryofplanning.org/images/Statistics/Final_Somaliland_ Infigures_2014.pdf. Accessed 20 July 2018.

12. Leather A, Ismail EA, Ali R, Abdi YA, Abby MH, Gulaid SA, et al. Working together to rebuild health care in post-conflict Somaliland. Lancet. 2006; 368(9541):1119-25.

13. Ahmed SH, Meyer HE, Kjøllesdal MK, Madar AA. Prevalence and predictors of overweight and obesity among Somalis in Norway and Somaliland: a comparative study. J Obes. 2018;2018:8.

14. Ministry Of Health-National Health Policy. Republic of Somaliland_Ministry of Health 2011.http://www.nhpcsomaliland.org/documents/ Somaliland\%20National\%20Health_Policy.pdf. Accessed 19 December 2018.

15. Scott A, Ejikeme CS, Clottey EN, Thomas JG. Obesity in sub-Saharan Africa: development of an ecological theoretical framework. Health Promot Int. 2013:28(1):4-16.

16. Unrepresented Nations \& People's Organization (UNPO). Member Profile: Somaliland in UNPO. Brussels, Belgium 2017. http://unpo.org/downloads/ 2343.pdf. Accessed 28 September 2018.

17. Keates AK, Mocumbi AO, Ntsekhe M, Sliwa K, Stewart S. Cardiovascular disease in Africa: epidemiological profile and challenges. Nat Rev Cardiol. 2017;14(5):273-93.

18. World Health Organization. WHO STEPS surveillance manual: The WHO STEPwise approach to chronic disease risk factor surveillance. 2017. https:// www.who.int/ncds/surveillance/steps/manual/en/. Accessed 26 Aug 2018.

19. Ahmed HA, et al. Prevalence of cardiovascular disease risk factors in urban Garissa residents. 2012.

20. Kish $L$, et al. A procedure for objective respondent selection within the household. J Am Stat Assoc. 1949:44(247):380-7.

21. Takahashi H, Yoshika M, Yokoi T. Validation of Omron RS8, RS6, and RS3 home blood pressure monitoring devices, in accordance with the European Society of Hypertension International Protocol revision 2010. Vasc Health Risk Manag. 2013:9:265-72.

22. Mean Body Mass Index (BMI)-Global Health Observatory (GHO) data by World Health Organization.https://www.who.int/gho/ncd/risk_factors/bmi_ text/en/.

23. International diabetes federation (IDF). The IDF consensus worldwide definition of the METABOLIC SYNDROME. 2006.

24. Laboratorium. FM. Hjerte-/karsykdom risikofaktorer tolkning Fürst Medisinsk Laboratorium. 2018. http//www.furst.no/analyse-og-klinikk/kliniske-problemstillinger/ hjerte-karsykdomrisikofaktorer/tolkning/. Accessed 28 Aug 2018.

25. World Health Organization. Global Physical Activity Questionnaire (GPAQ) for physical activity surveillance. 2004. http://www.who.int/ncds/ surveillance/steps/GPAQ/en/. Accessed 17 October 2018.

26. Dalal S, Beunza JJ, Volmink J, Adebamowo C, Bajunirwe F, Njelekela M, et al. Non-communicable diseases in sub-Saharan Africa: what we know now. Int J Epidemiol. 2011;40(4):885-901.

27. Noubiap JJN, Nansseu JRN, Bigna JJR, Jingi AM, Kengne AP. Prevalence and incidence of dyslipidaemia among adults in Africa: a systematic review and meta-analysis protocol. BMJ Open. 2015:5(3):e007404.

28. Peltzer K, Phaswana-Mafuya N. Fruit and vegetable intake and associated factors in older adults in South Africa. Glob Health Action. 2012:5. https:// doi.org/10.3402/gha.v5i0.18668. 
29. World Health Organization (WHO). Diet, nutrition and the prevention of chronic diseases: report of a joint WHO/FAO expert consultation. Geneva, Switzerland: WHO Technical Report Series; 2003. p. 916.

30. Lachat C, Otchere S, Roberfroid D, Abdulai A, Seret FMA, Milesevic J, et al. Diet and physical activity for the prevention of noncommunicable diseases in low- and middle-income countries: a systematic policy review. PLoS Med. 2013;10(6):e1001465

31. Batnitzky AK, et al. Cultural constructions of "obesity": understanding body size, social class and gender in Morocco. Health Place. 2011;17(1): 345-52.

32. Anand K, Shah B, Yadav K, Singh R, Mathur P, Paul E, et al. Are the urban poor vulnerable to non-communicable diseases? A survey of risk factors for non-communicable diseases in urban slums of Faridabad. Natl Med J India. 2007;20(3):115-20.

33. Li TY, Rana JS, Manson JE, Willett WC, Stampfer MJ, Colditz GA, et al. Obesity as compared with physical activity in predicting risk of coronary heart disease in women. Circulation. 2006;113(4):499-506.

34. Guthold R, Stevens GA, Riley LM, Bull FC. Worldwide trends in insufficient physical activity from 2001 to 2016: a pooled analysis of 358 populationbased surveys with 1.9 million participants. Lancet Glob Health. 2018;6(10): e1077-e86.

35. Donnelly TT, ABM A-T, Benjamin K, Al-Khater A-H, Fung TS, Ahmedna M, et al. Arab female and male perceptions of factors facilitating and inhibiting their physical activity: Findings from a qualitative study in the Middle East. PLoS One. 2018;13(7):e0199336-e.

36. Sharara E, Akik C, Ghattas H, Makhlouf Obermeyer C. Physical inactivity, gender and culture in Arab countries: a systematic assessment of the literature. BMC Public Health. 2018;18(1):639.

37. Al-Dubai SA, Rampal KG. A cross-sectional study on chewing khat and tobacco smoking among doctors in Yemen. Circulation. 2012;125(19):E733-E.

38. Bush J, White M, Kai J, Rankin J, Bhopal R. Understanding influences on smoking in Bangladeshi and Pakistani adults: community based, qualitative study. BMJ. 2003;326(7396):962.

39. Omar YS, Jenkins A, Altena MR, Tuck H, Hynan C, Tohow A, et al. Khat use: what is the problem and what can be done? J BioMed Research International. 2015;2015:7.

40. Sreeramareddy CT, Pradhan PM, Sin S. Prevalence, distribution, and social determinants of tobacco use in 30 sub-Saharan African countries. BMC Med. 2014;12(1):243

41. O'Donnell CJ, Elosua R. Cardiovascular risk factors. Insights from Framingham heart study. Revista Española de Cardiología (English Edition). 2008;61(03):299-310.

42. Ageely HMA. Health and socio-economic hazards associated with khat consumption. J Family Community Med. 2008;15(1):3-11.

43. Mohamed Ibrahim, Bushra Hussein A. Malik, Gameraddin M. Doppler assessment of the effect of chewing Qat on hemodynamics of the common carotid arteries. J Med Sci 2017.

44. Tesfaye F, Byass P, Wall S, Berhane Y, Bonita R. Association of Smoking and Khat (Catha edulis Forsk) use with high blood pressure among adults in Addis Ababa, Ethiopia, 2006. Prev Chronic Dis. 2008:5(3):A89.

45. Al-Motarreb A, Briancon S, Al-Jaber N, Al-Adhi B, Al-Jailani F, Salek MS, et al. Khat chewing is a risk factor for acute myocardial infarction: a case-control study. Br J Clin Pharmacol. 2005;59(5):574-81.

46. Girma T, Mossie A, Getu Y. Association between body composition and khat chewing in Ethiopian adults. BMC Res Notes. 2015;8:680.

47. Olawuyi AT, Adeoye IA. The prevalence and associated factors of noncommunicable disease risk factors among civil servants in Ibadan, Nigeria. PLoS One. 2018;13(9):e0203587-e.

48. Cappuccio FP, Miller MA. Cardiovascular disease and hypertension in subSaharan Africa: burden, risk and interventions. Intern Emerg Med. 2016;11(3): 299-305.

49. Devi S. Slowly and steadily, Somaliland builds its health system. Lancet. 2015;385(9983):2139-40.

50. Németh $\mathrm{R}$ et al, Respondent selection within the household-a modification of the Kish Grid 2001.

\section{Publisher's Note}

Springer Nature remains neutral with regard to jurisdictional claims in published maps and institutional affiliations.

\section{Ready to submit your research? Choose BMC and benefit from:}

- fast, convenient online submission

- thorough peer review by experienced researchers in your field

- rapid publication on acceptance

- support for research data, including large and complex data types

- gold Open Access which fosters wider collaboration and increased citations

- maximum visibility for your research: over $100 \mathrm{M}$ website views per year

At $\mathrm{BMC}$, research is always in progress.

Learn more biomedcentral.com/submissions 